\title{
Computer Model for Railway Inductive Power Supply Using the Valtchev Model
}

\author{
Joao Victor Pinon Pereira Dias *, Hyungchul Kim ** and Donguk Jang ***
}

\begin{abstract}
This paper presents contactless power supply systems using the Valtchev model in transportation systems. The major drawback of contactless systems is that the efficiency is lower than that of contact systems. The coupling coefficient of the contactless transformer is the most influential parameter on the system efficiency. Here, a new computer model for the contactless transfer system developed in the Korea Railroad Research Institute is presented. Also, simulations of the old model and the new model are compared with the prototype measurement to assure the model validity.
\end{abstract}

Keywords: Railway, Contactless power supply systems, Coupling coefficient

\section{Introduction}

Electrical supply systems for railway are based on contact systems. Contact systems can be divided in catenary systems and third rails. Even though, these systems are widely used, they have electric arc problems.

With the intention of creating a maintenance free system, with no mechanical contact between the supply and the load and with no electric shock hazard, contactless power transfer systems were built.

Contactless power transfer can be based on electromagnetic or mechanic waves; moreover, the constructed systems use electromagnetic fields applied in inductive coupling system, with or without magnetic cores [1].

The essence of an inductive coupling contactless transfer system is the presence of transformers with a big air gap between the primary side and the secondary side.

The separation of the cores produces a small coupling of the coils, and bigger leakages inductances than magnetizing inductances, culminating in a small coupling coefficient. To overcome these limitations, compensation with high frequency converters are used [2].

In transportation systems, contactless power supply systems are being used in a people mover system [3], and in an electric bus [4]-[5], replacing traditional contact systems.

In railway systems contactless power transfer is used in light rail and maglev trains. Bombardier has developed the PRIMOVE technology to be used in light rail especially in

\footnotetext{
* University of Science \& Technology, KRRI Campus, Korea. (jvppd1@krri.re.kr)

** Metropolitan Railroad Research Center, Korea Railroad Research Institute, Korea (hckim@krri.re.kr)

*** Metropolitan Railroad Research Center, Korea Railroad Research Institute, Korea ( dujang@krri.re.kr)

Received 10 July 2011; Accepted 30 October 2011
}

downtown areas [6]. ThyssenKrupp has developed the Inductive Power Supply, IPS, to be used in the T09 Transrapid [7].

Besides being used in transportation systems contactless power transfer is also used in other applications like robotics [1] and biomedicine [8].

In Korea Railroad Research Institute a contactless energy transfer system has also been designed. The Railway Inductive Power Supply System (RIPS) consists of a power inverter, contactless transformer, resonance circuit and a rectifier.

The contactless transformer is formed by to parts, the primary side and the secondary side. The primary side has a long coreless coil and the secondary side has a coil wound in a ferrite core. The inverter uses IGBT drives and the rectifier uses diodes.

The RIPS supplies energy to a prototype, which moves on a small rail. Electric characteristic models were built and simulated using computational tools.

This paper proposes a new computational model for the RIPS, based in the model presented by Valtchev in [9]. The model uses the coupling coefficient to represent the low coupling between the coils of the contactless transformer instead of the value of magnetizing inductance.

With the proposition of this new computational model it will be easier to change the parameters of the system to improve the efficiency, reduce power consumption and test changes in the air gap and resonance frequency.

\section{Modeling}

\subsection{Contactless Transformer}

The characteristics of RIPS, as with the other contactless transfer systems, depends mainly on the 
contactless transformer. Moreover, the modeling is focused on the accuracy representation of the electric characteristics of the contactless transformers.

The RIPS is shown in Fig. 1 and Fig. 2. The system is composed of inverter, match transformer, resonant inductor, primary compensation capacitors, contactless transformer, secondary compensation capacitors, rectifier, motor drive and DC motor.

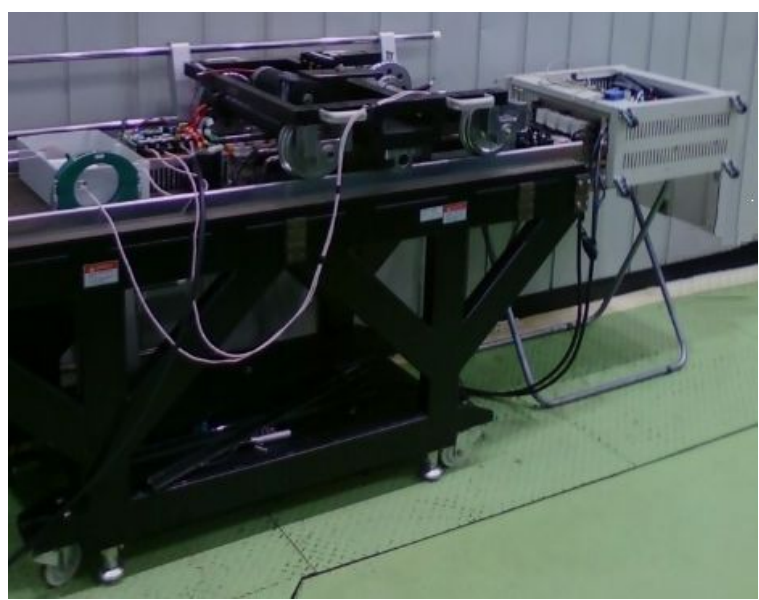

Fig. 1. RIPS

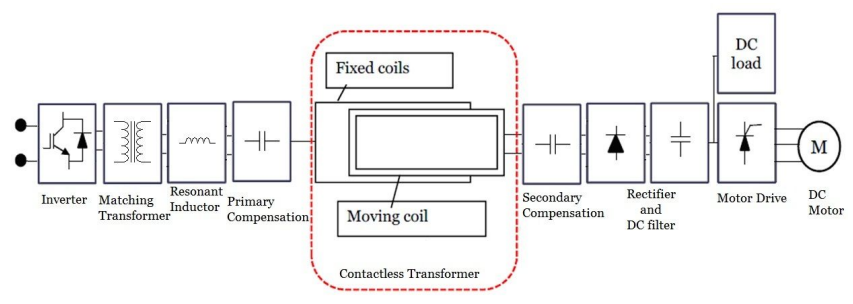

Fig. 2. Diagram of RIPS system

The inverter, the rectifier and the motor drive will be considered as ideal switches, because the analysis of characteristics each one of these devices is out of the scope in this paper.

The main parameter of contactless transformers is the coupling coefficient, $k,[8]$. The coupling coefficient measures the magnetic coupling between the primary and secondary coils. The value of $\mathrm{k}$ also represents the quantity of the linked flux of the primary coil that links the secondary coil. Equations (1) to (14) are proposed by [10]

To measure the value of $k$ the following equation is used:

$$
k=\frac{M}{\sqrt{L_{1} L_{2}}}
$$

where $M$ is the mutual inductance between the cores, $L_{l}$ and $L_{2}$ are the primary and secondary self-inductances respectively.

To measure the value of $M$, the inductance of the coils is measured in series-adding mode, $L_{a}$ and series-opposing, $L_{b}$ as shown in Fig. 3. The value of $\mathrm{M}$ follows:

$$
M=\left(L_{a}-L_{b}\right) / 4
$$
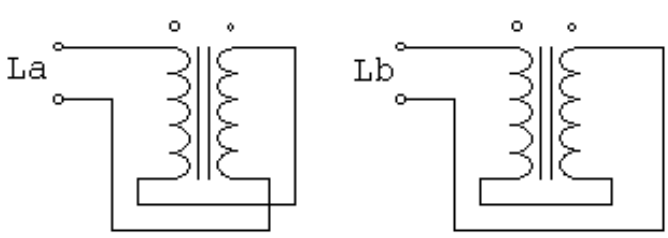

Fig. 3. Measure of $\mathrm{L}_{\mathrm{a}}$ and $\mathrm{L}_{\mathrm{b}}$

The self-inductance of the coils is represented:

$$
\begin{aligned}
& L_{1}=L_{l 1}+L_{m} \\
& L_{2}=L_{l 2}+L_{m s}
\end{aligned}
$$

where $L_{l l}$ and $L_{m}$ are the leakage inductance and the magnetizing inductance of the primary and $L_{l 2}$ and $L_{m s}$ are the leakage inductance and the magnetizing inductance of the secondary.

It is also possible to write the leakage and magnetizing inductances related to $k$ as follows:

$$
\begin{aligned}
& L_{l 1}=L_{1}(1-k) \\
& L_{l 2}=L_{2}(1-k) \\
& L_{m}=k L_{1} \\
& L_{m s}=k L_{2}
\end{aligned}
$$

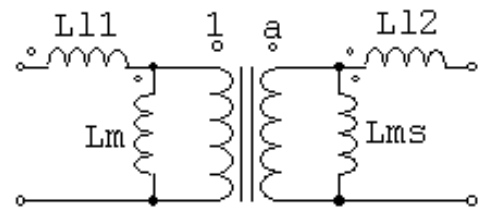

Fig. 4. Transformer model with leakage and magnetizing inductances

Fig. 4 shows the model of an ideal transformer with leakage and magnetizing inductances. In contactless transformers leakage inductances can't be neglected. The presence of the leakage inductances divides into the input current in magnetizing and leakage current, being induced to the secondary side only the magnetizing current. The reduction in the secondary current implies in the necessity to redefine the transformer turns ratio. 
The new ratio, $a$, depends on the value of the selfinductances and the coupling coefficient. The primary winding of the contactless transformer is considered with 1 turn, then $a$ is express as:

$$
a=k \frac{\sqrt{L_{2}}}{\sqrt{L_{1}}}
$$

After defining all the electric characteristics of the contactless transformer, it is necessary to say that some modeling approaches have been use in different references. In Reference [1] the leakage inductance are considering in both primary and secondary sides and the primary magnetizing inductance.

In References [2] and [11] only the inductances of the primary side are used in the electric model. Before the research that lead to this paper this was the model used to represent the contactless transformer of the RIPS.

The new modeling of the RIPS is based on the model proposed by Vatchev et. al. in [9], where only the selfinductances are used in the model, although fictional inductances are added to the primary and the secondary to represent the effect of the magnetizing current.

In the primary side the fictional inductance value is equal to the leakage inductance multiplied by $k$; moreover in the secondary side the inductances are of the primary are divided by the coupling coefficient.

\subsection{Resonance Circuit}

After defining the model of the RIPS, it is necessary to analyze resonance circuits to compensate the reactive power of the contactless transformer. The best scenario is that the power transfer is maximum when a pure resistive load is connected to the source.

In the presented model of the contactless transformer, inductances can't be neglected and the impedance of the system became inductive. For compensate the inductive reactance, capacitors should be installed.

The compensation can be in parallel or in series, and the results regarding the impedance are the same when parallel or series compensation are used, the difference remains in the relation between the capacitances.

The following equation shows how to calculate the compensation capacitor:

$$
f=\frac{1}{2 \pi \sqrt{L C}}
$$

where $f$ is the frequency of the input signal in the resonance circuit, $L$ and $C$ are the inductance and the capacitance of the branch respectively.

In Reference [1] the transfer function of both compensation schemes are constructed and it is proved that in the case of parallel compensation, the value of the secondary capacitor in relation of the primary depends on $k$ value. In transportation system the air gap can change, changing the value of coupling coefficient. Therefore series compensation is used in the RIPS circuit.

To calculate the primary compensation, $C_{p}$ is used as the value of the primary leakage inductance plus the resonant inductance, as follows:

$$
C_{p}=\frac{1}{(2 \pi \cdot f)^{2}\left(L_{l l}+L_{r}\right)}
$$

The secondary compensation, $C_{s m}$, when the magnetizing inductance is considered is calculated as follows:

$$
C_{s m}=\frac{1}{(2 \pi . f . a)^{2} L_{m}}
$$

In the case of the secondary leakage inductance, $C_{s l}$ :

$$
C_{s l}=\frac{1}{(2 \pi . f .)^{2} L_{l 2}}
$$

Finally with the intention of representing the dc load in the ac system, the equivalent value is proposed in [1] and [11] as follows:

$$
R_{a c}=\frac{8}{\pi^{2}} R_{d c}
$$

\subsection{Electric Circuits}

After presenting all the modeling used to construct the RIPS, both circuits is shown; the previous approach based in [2] and [11] and further, the new model based in [9].

To match the characteristics of current and voltage of the DC motor used in the prototype, a match transformer and a reactance inductor are used. Fig. 5 represents the current approach of the RIPS circuit while Fig. 6 shows the novel approach.

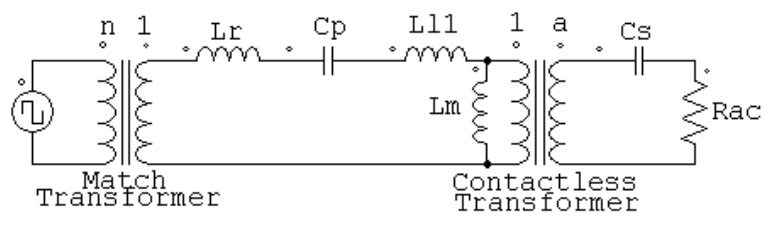

Fig. 5. Previous RIPS circuit 


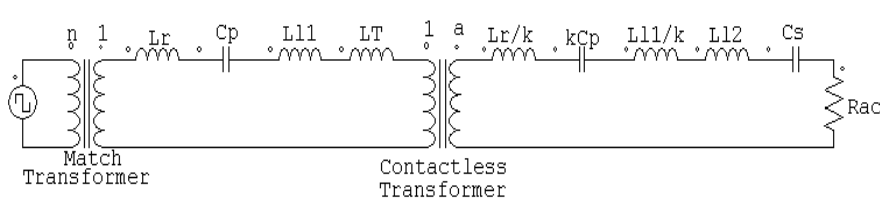

Fig. 6. Novel approach.

\section{Simulation}

The simulations are performed in the PSIM software, and both the actual model and the new model will be analyzed. The circuits are presented in Fig. 7 and Fig. 8.

Table I shows the parameters of the RIPS circuit; the measurements of the inductances were performed using a LCR Meter. Due to the constructive characteristic of the inverter drive, the switching frequency is $20 \mathrm{kHz}$.

Table 1. RIPS Parameters

\begin{tabular}{|c|c|}
\hline Series-aiding inductance $\left(\mathrm{L}_{\mathrm{a}}\right)$ & $314.70 \mathrm{uH}$ \\
\hline Series-opposing inductance $\left(\mathrm{L}_{\mathrm{b}}\right)$ & $224.79 \mathrm{uH}$ \\
\hline Mutual inductance (M) & $22.48 \mathrm{uH}$ \\
\hline Primary self-inductance $\left(\mathrm{L}_{1}\right)$ & $3.15 \mathrm{uH}$ \\
\hline Secondary-self-inductance $\left(\mathrm{L}_{2}\right)$ & $265.65 \mathrm{uH}$ \\
\hline Resonance-inductor $\left(\mathrm{L}_{\mathrm{r}}\right)$ & $4.67 \mathrm{uH}$ \\
\hline Coupling coefficient (k) & 0.77 \\
\hline $\begin{array}{c}\text { Primary leakage inductance } \\
\left(\mathrm{L}_{11}\right)\end{array}$ & $0.73 \mathrm{uH}$ \\
\hline $\begin{array}{c}\text { Secondary leakage inductance } \\
\left(\mathrm{L}_{12}\right)\end{array}$ & $60.67 \mathrm{uH}$ \\
\hline $\begin{array}{l}\text { Primary magnetizing } \\
\text { inductance }\left(\mathrm{L}_{\mathrm{m}}\right)\end{array}$ & $2.47 \mathrm{uH}$ \\
\hline $\begin{array}{c}\text { Secondary magnetizing } \\
\text { inductance }\left(\mathrm{L}_{\mathrm{ms}}\right)\end{array}$ & $204.98 \mathrm{uH}$ \\
\hline $\begin{array}{l}\text { Contactless transformer ratio } \\
\text { (a) }\end{array}$ & 7.04 \\
\hline Primary compensation $\left(\mathrm{C}_{\mathrm{p}}\right)$ & $11.71 \mathrm{uF}$ \\
\hline $\begin{array}{l}\text { Secondary magnetizing } \\
\text { compensation }\left(\mathrm{C}_{\mathrm{sm}}\right)\end{array}$ & $0.52 \mathrm{uF}$ \\
\hline $\begin{array}{l}\text { Secondary leakage } \\
\text { compensation }\left(\mathrm{C}_{\mathrm{sl}}\right) \\
\end{array}$ & $1.04 \mathrm{uF}$ \\
\hline Match transformer ratio (n) & 2.75 \\
\hline $\mathrm{L}_{\mathrm{T}}$ & $0.56 \mathrm{uH}$ \\
\hline $\mathrm{L}_{\mathrm{r}} / \mathrm{k}$ & $6.02 \mathrm{uH}$ \\
\hline $\mathrm{kC}_{\mathrm{p}}$ & $9.03 \mathrm{uF}$ \\
\hline $\mathrm{L}_{11} / \mathrm{k}$ & $0.94 \mathrm{uH}$ \\
\hline
\end{tabular}
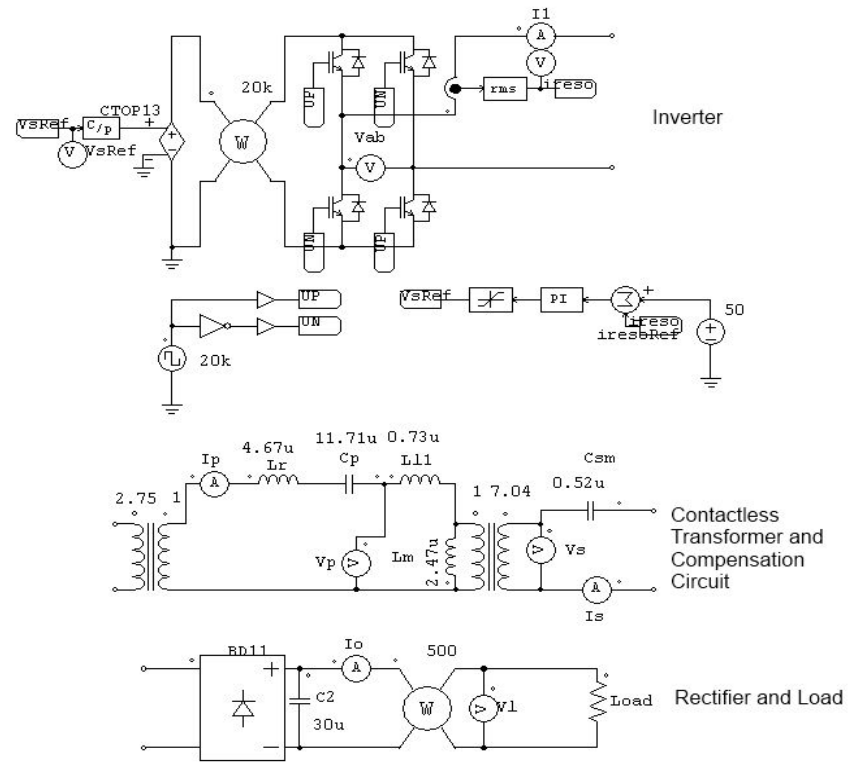

Fig. 7. Actual RIPS circuit model

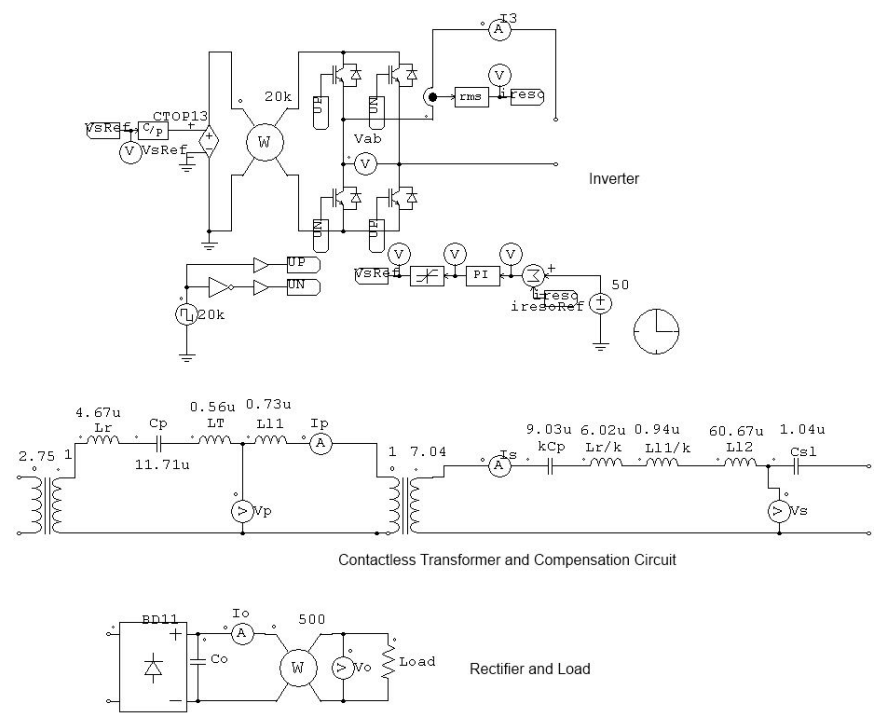

Fig. 8. Novel RIPS circuit model

To analyze the quality of the models, the waveforms of the input and output currents and the voltages in the contactless transformer are analyzed. To simulate the real operation of the prototype the reference voltage of the inverter will be restricted.

The input voltage of the contactless transformer is chosen to be the reference voltage for the models and the prototype. The decided value is $15.7[\mathrm{~V}]$; because this is the first value that permits the operation of the DC motor between $90[\mathrm{~V}]$ and $100[\mathrm{~V}]$; rated voltage for the motor used in the RIPS.

Fig. 9 and 10 shows the results of the simulation of the current model; moreover, Fig. 11 and 12 the results for the innovative model. 

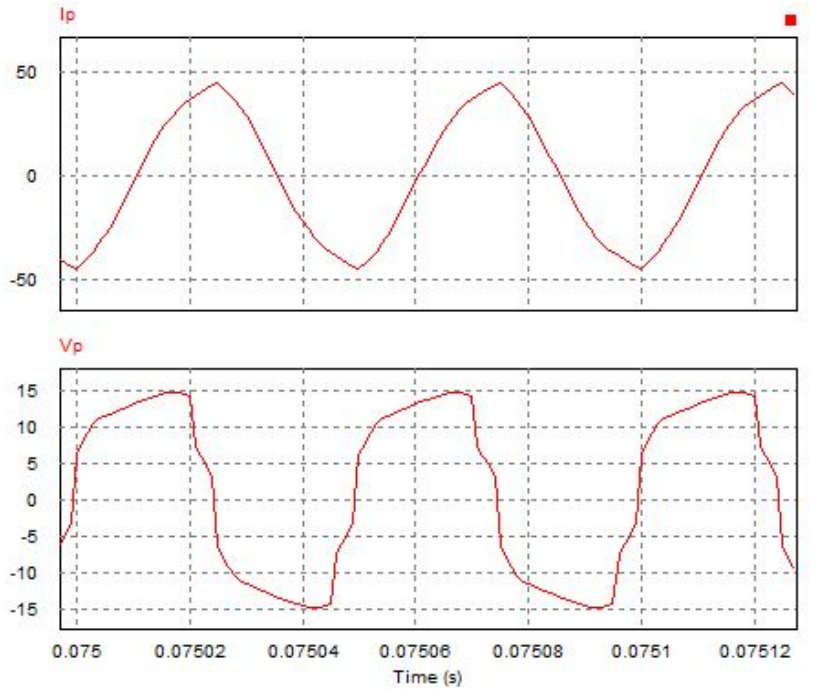

Fig. 9. Input current and voltage Old model
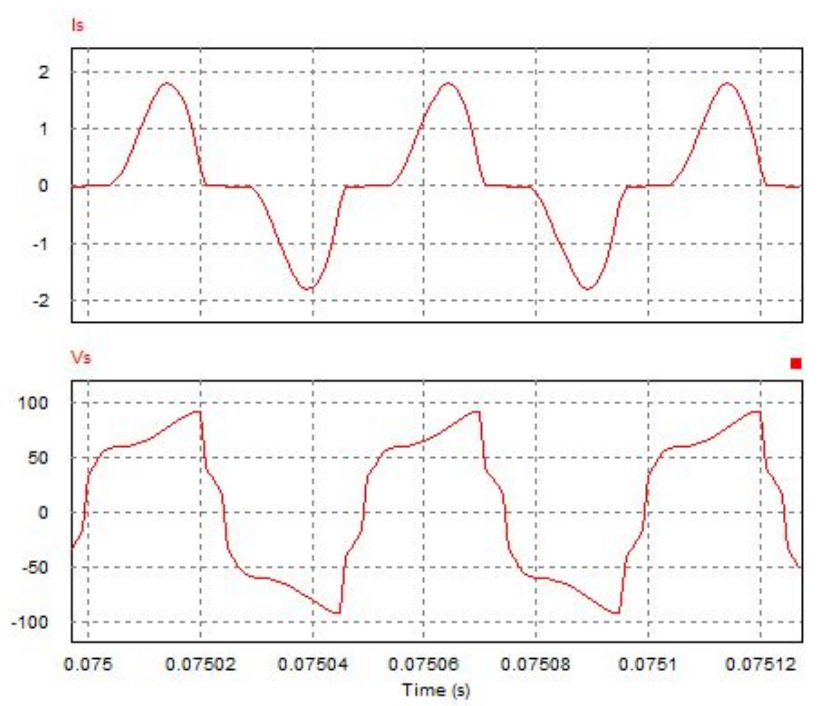

Fig. 10. Output current and voltage Old model
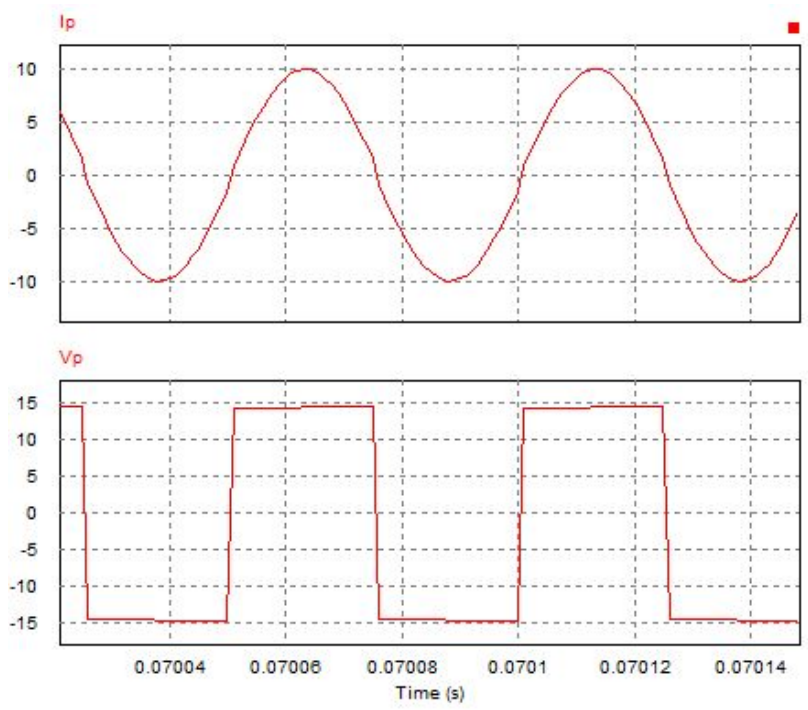

Fig. 11. Input current and voltage Novel model
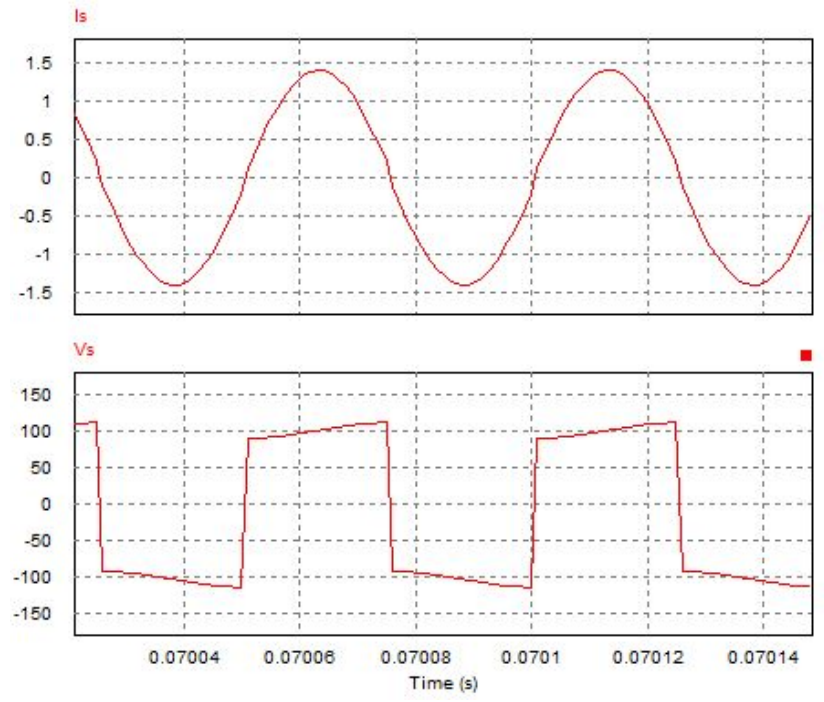

Fig.12. Output current and voltage Novel model

Analyzing both input wave forms, it is possible to see that a) in the old model has a distortion near the current peak value; b) the voltage should be similar to a square wave what is not occurring. These effects are caused because the circuit needs more capacitive compensation. Another characteristic is that the current and voltage are out of phase.

On the other hand the output voltage of the new model is much higher than the one allowed in the DC motor.

\section{Experimental Results and Discussion}

The measurements in the prototype are performed using a LeCroy Wave Runner oscilloscope. To acquire the current a current probe is used. The current probe ratio is $1 \mathrm{~V}$ to 0.1 A. The capacitances used in the primary and the secondary compensation circuits were measured using a LCR Meter and their values are $C_{p}=11.301[\mathrm{uF}]$ and $C_{s}=360[\mathrm{nF}]$.

Fig.13 to Fig. 16 represent the input and output current and voltages of the contactless transformer for two scenarios, in Table 2 the channels of the oscilloscope are related to one of the parameters of the contactless transformer.

Table 2. Oscilloscope Channel

\begin{tabular}{|c|c|}
\hline Channel & Contactless Transformer Parameter \\
\hline C1 & Input Voltage \\
\hline C2 & Input Current \\
\hline C3 & Output Voltage \\
\hline C4 & Output Current \\
\hline
\end{tabular}

The waveforms of the prototype are related to two different scenarios. In a first moment the load is a resistance and the car in not in motion, after that the motor drive is connected and the same parameters are measured and the waveforms are shown. 
Fig. 13 shows the input current and voltage of the contactless transformer. Fig. 14 shows the output current and voltage of the contactless transformer.

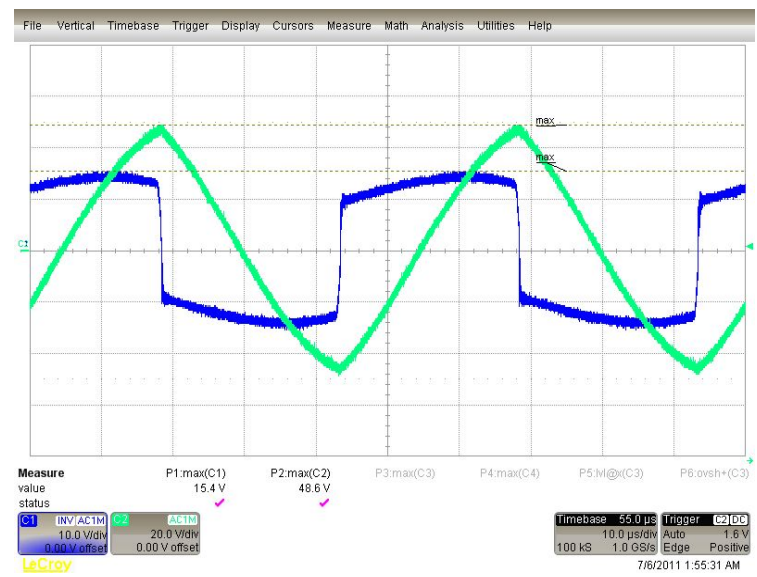

Fig. 13. Input current and voltage of the contactless transformer - Steady State

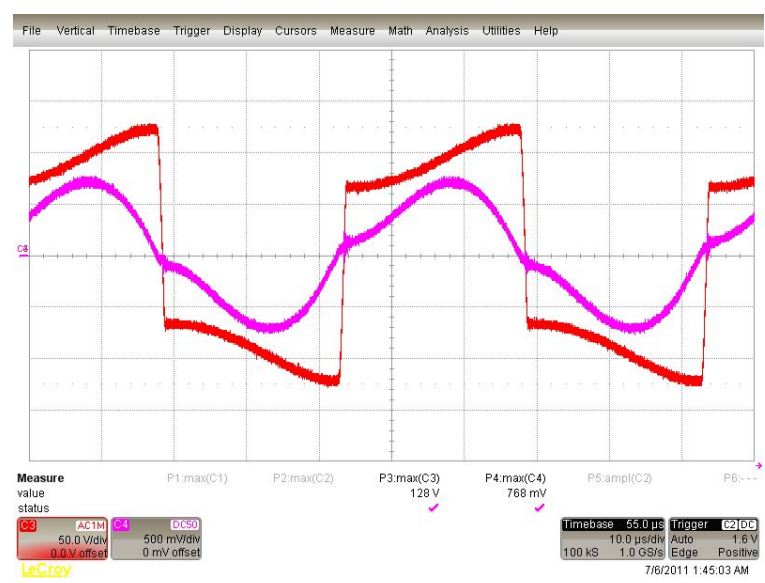

Fig. 14. Output current and voltage of the contactless transformer - Steady State

After connecting the motor drive the current and voltage in the contactless transformer is measured again and they are presented in Fig. 15 and 16.

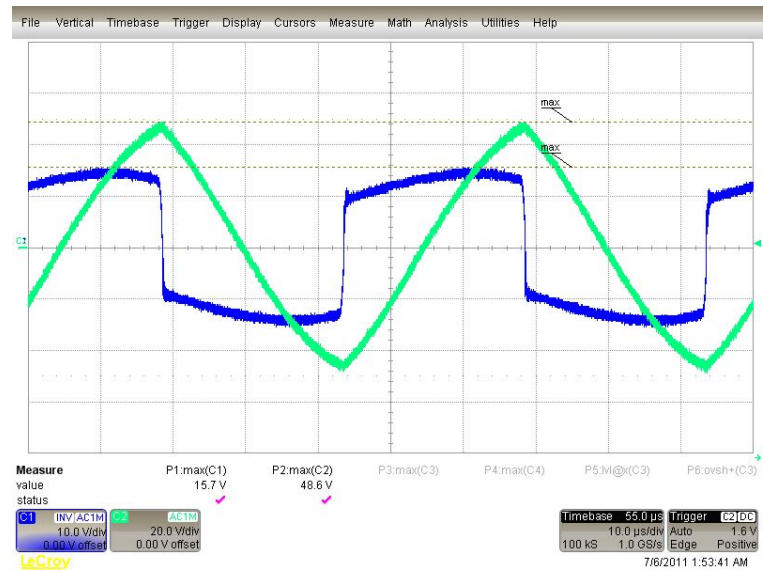

Fig. 15. Input current and voltage of the contactless transformer - Moving

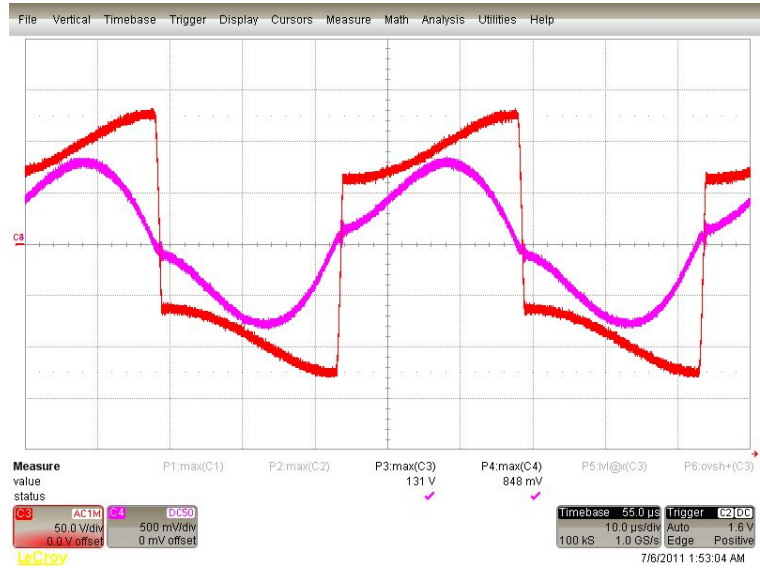

Fig. 16. Output current and voltage of the contactless transformer - Moving

As show in the waveforms of the input and output of the contactless transformer the current and the voltage increase after the connection of the DC motor.

The input waveforms show that the current and the voltage are not in phase. Moreover in the output they are in phase, following the results of the simulations

In the input wave form current has a triangular shape and the voltage a square shape, although the output current shape is more near to a sinusoidal signal and the voltage has a sloped curve at the top.

By analyzing the input and the output, it is possible to analyze that the turn ratio between the primary and the secondary sides are different from the simulations, and smaller than the expected value, causing a smaller value of the output current and voltage.

When comparing the simulations with the measurements, it is possible to say that in terms of the primary side, the previous model had more accuracy, on the other hand on the secondary side the new model represents better the output current and voltage.

\section{Conclusion}

A new computer model for the RIPS is proposed using the software PSIM. The new model is compared with the actual model and both are compared with the prototype measurements.

From the comparison of the models with the prototype, it is possible to say that the actual model better represents the primary side response. On the other hand the novel model better represents the response of the secondary side.

The measured current is smaller than the calculated current in both models, probably due to the effect of the loose coupled coils, which are greater than expected and adjustments in the model should occur to represent the RIPS prototype better.

Further studies will be in the direction of combining the two models to represent the RIPS characteristics more 
accurately. The interaction between the two coils will be studied more deeply to confront the results of this paper and the prototype measurements.

\section{Acknowledgements}

This work was supported by the Korea Railroad Research Institute.

\section{References}

[1] A. J. Moradewicz and M. P. Kazmierkowski, "Contactless Energy Transfer System With FPGA-Controlled Resonant Converter," IEEE Transactions on Industrial Electronics, Vol. 57, No. 9, pp. 3181-3190 September 2010.

[2] M. Ryu, J. Kim, J Baek and H. Cha "Analysis of the Contactless Power Transfer System Using Modeling and Analysis of Contactless Transformer", Journal of Electrical Engineering \& Technology, Vol. 1, No 3, pp. 351-358, June 2006.

[3] G.A. Covic, G. Elliott, O.H. Stielau, R. M. Green and J.T. Boys, "The design of a contact-less energy transfer system for a people mover system," PowerCon 2000: International Conference on Power System Technology, 04-07 December 2000, Perth, Australia.

[4] S. Lee, C. Park, G. H. Cho, J. H, N. S. Choi and C. H. Taek "On-Line Electric Vehicle using Inductive Power Transfer System”, ECCE 2010, Energy Conversion Congress and Exposition, 12-16 September 2010, Atlanta, USA.

[5] J. L. Villa, J. Sallan, A. Llombart and J. F. Sanzi, "Design of a high frequency Inductively Coupled Power Transfer system for electric vehicle battery charger," Applied Energy, Vol. 86, No. 3, pp. 355-363, March 2009.

[6] www.bombardier.com

[7] M. Bauer, P. Becker and Q. Zhengl, "Inductive Power Supply (IPS®) for the Transrapid", MAGLEV 2006: The 19th International Conference on Magnetically Levitated Systems and Linear Drives, 13-15 September 2006, Dresden, Germany.

[8] W. Zhang, Q. Chen, S. C. Wong, C. K. Tse and X. Ruan, “A Novel Transformer for Contactless Energy Transmission Systems," ECCE 2009: Energy Conversion Congress and Exposition, 20-24 September 2009, San Jose, USA.

[9] S. Valtchev, B. Borges, K. Brandisky, and J. B. Klaassens, "Resonant Contactless Energy Transfer With Improved Efficiency," IEEE Transactions on Power Electronics, Vol. 24, No. 3, pp. 685-699 March 2009.

[10] M. K. Kazimierczuk "High-Frequency Magnetic Components", 1 Ed

[11] C. S. Lin, S. G. Lin, C. F. Chang, H. H. Li and T. R. Chen "Model of Contactless Power Transfer System for Linear Track" PEDS2009. International Conference on Power Electronics and Drive Systems, 2-5 November 2009, Taipei, Taiwan.

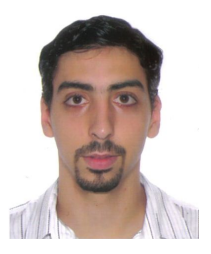

Joao Victor Pinon Pereira Dias received his B.S degree in electrical engineering from State University of Campinas, Brazil in 2008. His research interests are Electric Traction Systems and Transformers for Railway applications.

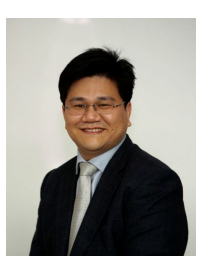

Hyungchul Kim received the B.S. and M.S. degrees in electrical engineering from Korea University, Seoul, Korea, in 1991 and 1993, respectively, and his Ph.D. degree from Texas A\&M University, College Station, USA in 2003 . He is presently working for Korea Railroad Research Institute, Korea.

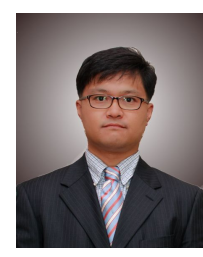

Donguk Jang received his B.S degree and M.S degree in electrical engineering from Chungbuk National University. His research interests include power supply systems, high voltage engineering and insulation diagnosis for railway systems. 